\title{
openheart Prosthetic aortic valve selection: current patient experience, preferences and knowledge
}

\author{
Nelleke M Korteland, ${ }^{1}$ Frans J Bras, ${ }^{2}$ Fabienne M A van Hout, ${ }^{3}$ Jolanda Kluin, ${ }^{2}$ \\ Robert J M Klautz, ${ }^{3}$ Ad J J C Bogers, ${ }^{1}$ Johanna J M Takkenberg ${ }^{1}$
}

To cite: Korteland NM, Bras FJ, van Hout FMA, et al. Prosthetic aortic valve selection: current patient experience, preferences and knowledge. Open Heart 2015;2: 000237. doi:10.1136/openhrt-2015000237

- Additional material is available. To view please visit the journal (http://dx.doi.org/ 10.1136/openhrt-2015000237)

Received 6 January 2015 Revised 10 March 2015 Accepted 17 March 2015

\section{(a) CrossMark}

${ }^{1}$ Department of CardioThoracic Surgery, Erasmus MC, Rotterdam, The Netherlands

${ }^{2}$ Department of CardioThoracic Surgery, UMC Utrecht, Utrecht, The Netherlands

${ }^{3}$ Department of CardioThoracic Surgery, LUMC, Leiden, The Netherlands

Correspondence to Dr Johanna JM Takkenberg; j.j.m.takkenberg@ erasmusmc.nl

\section{ABSTRACT}

Objective: Current clinical practice guidelines advocate shared decision-making (SDM) in prosthetic valve selection. This study assesses among adult patients accepted for aortic valve replacement (AVR): (1) experience with current clinical decision-making regarding prosthetic valve selection, (2) preferences for SDM and risk presentation and (3) prosthetic valve knowledge and numeracy.

Methods: In a prospective multicentre cohort study, AVR patients were surveyed preoperatively and 3 months postoperatively.

Results: 132 patients (89 males/43 females; mean age 67 years (range 23-86)) responded preoperatively. Decisional conflict was observed in $56 \%$ of patients, and in $25 \%$ to such an extent that it made them feel unsure about the decision. $68 \%$ wanted to be involved in decision-making, whereas $53 \%$ agreed that they actually were. $69 \%$ were able to answer three basic knowledge questions concerning prosthetic valves correctly. $56 \%$ were able to answer three basic numeracy questions correctly. Three months postsurgery, $90 \%(n=110)$ were satisfied with their aortic valve prosthesis, with no difference between mechanical and bioprosthetic valve recipients.

Conclusions: In current clinical practice, many AVR patients experience decisional conflict and suboptimal involvement in prosthetic valve selection, and exhibit impaired knowledge concerning prosthetic valves and numeracy. Given the broad support for SDM among AVR patients and the obvious need for understandable information, to-be-developed tools to support SDM in the setting of prosthetic valve selection will help to improve quality of decision-making, better inform and actively involve patients, and reduce decisional conflict. Trial registration number: NTR3618.

\section{INTRODUCTION}

For most patients who require aortic valve replacement (AVR), two options exist: mechanical or bioprosthetic valve replacement. Each prosthetic valve has specific risks and benefits. Mechanical valves are thrombogenic and therefore require lifelong anticoagulation. Bioprosthetic valves carry a higher risk

\section{KEY MESSAGES}

What is already known about this subject?

- Shared decision-making (SDM) receives more and more attention in healthcare. Prosthetic aortic valve selection concerns a value sensitive decision. The 2014 ACC/AHA Valvular Heart Disease Guidelines and 2012 ESC/EACTS guidelines highlight the importance of SDM.

What does this study add?

- However, the attitude of patients towards SDM in prosthetic aortic valve selection remains unexplored. Therefore, we conducted a prospective multicentre cohort study among elective adult aortic valve replacement (AVR) patients.

How might this impact on clinical practice?

- We are convinced that our observations provide an important information base on which we can build effective tools for the implementation of SDM in prosthetic aortic valve selection. This will result in better informed patients who feel more responsible for their own health and disease management, and it will hopefully lead to better informed decisionmaking and better quality of care.

of reoperation due to valve degeneration. ${ }^{1}{ }^{2}$ There is no apparent difference in survival for adult patients with a mechanical or bioprosthetic valve. ${ }^{3} 4$ Therefore, prosthetic valve choice is mainly driven by valve-specific risks and benefits. Given the different nature of these risks and benefits for mechanical and bioprosthetic valves, informed patient preferences deserve consideration in decision-making.

The 2014 ACC/AHA Valvular Heart Disease Guidelines state that prosthetic valve choice should be a shared decision process, ${ }^{2}$ while the 2012 ESC/EACTS guidelines highlight the importance of considering informed patient preferences (Class 1 recommendations). ${ }^{1}$ We previously showed that the majority of the Dutch cardiothoracic surgeons and cardiologists are of the opinion that 
prosthetic aortic valve selection should ideally be done together with the patient and they report to communicate to the patient most important risks of the different prosthetic valve types. Nevertheless, only half of them actively involves patients in prosthetic valve selection. ${ }^{5}$ Although the guidelines advocate shared decision-making (SDM), clinicians do not have any tools to engage this activity.

In order to engage in SDM, both the clinician and the patient should be able and willing to participate. It is unknown how patients experience decision-making in prosthetic aortic valve selection and what their attitude is towards SDM. The purpose of this prospective study was to assess among adult patients accepted for AVR: (1) experience with current clinical decision-making regarding prosthetic valve selection, (2) preferences for SDM and risk presentation and (3) prosthetic valve knowledge and numeracy.

\section{METHODS}

This study was approved by the institutional review board of all three participating centres (Erasmus MC MEC nr. 12-323). Written informed consent was obtained. Participants were adult patients who were accepted for elective AVR in one of the three hospitals between September 2012 and June 2013. Patients had to be legally capable. Two surveys were conducted, one preoperatively after preoperative outpatient counselling, and another 3 months postoperatively.

\section{Preoperative survey}

Patient experience with prosthetic valve selection

Multiple choice (MC) questions assessed which clinician (surgeon, cardiologist, both or other) performed the preoperative consultation with regard to prosthetic valve choice, if a friend or family member was involved in prosthetic valve choice, patient opinion on the amount of time available for prosthetic valve choice, and how patients valued their participation in prosthetic valve choice.

The Decisional Conflict Scale (DCS) was used to measure the degree of uncertainty about which course of action to take and the main modifiable factors contributing to uncertainty. It is a 16-item questionnaire with five subscales: uncertainty, informed, values clarity, support and effective decision. Total scores $<25$ are associated with no decisional conflict and implementation of decision. Scores exceeding 25 are associated with decisional conflict, with higher scores indicating higher decisional conflict. Scores $\geq 37.5$ are associated with decision delay or feeling unsure about implementation. ${ }^{6}$

A 1-5 Likert scale was used to assess how patients value the importance of the different risks and benefits associated with a mechanical and bioprosthetic valve.

Patient preferences for SDM and risk presentation

A 1-5 Likert scale and a Control Preferences scale were used to assess patient view on participation in decision-making. ${ }^{7}$
Patient preference for presentation of scientific evidence was assessed by asking patients to rate four graphical formats of scientific evidence: a horizontal bar, pie chart and two pictographs (a visual presentation of data) ${ }^{8}$

Patient prosthetic valve knowledge and numeracy

Information that patients perceived from the treating physician with regard to prosthetic valve selection and patient knowledge regarding the risks and benefits associated with mechanical and bioprosthetic valves was assessed by MC questions and a 1-5 Likert scale.

Patient numeracy was assessed using the Numeracy Scale. $^{9}$

For a detailed description of the preoperative survey, see online supplementary appendix 1 .

\section{Postoperative survey}

Patient experience with prosthetic valve selection

MC questions and a 1-5 Likert scale were used to assess patient opinion on the amount of time available for prosthetic valve choice, how patients value their participation in prosthetic valve choice, and patient satisfaction with the type of prosthetic valve they received.

Valve-specific quality of life (QoL) was measured with a valve-specific questionnaire. ${ }^{10}$

\section{Patient preferences for SDM}

Patient view on participation in decision-making was assessed by a 1-5 Likert scale and a Control Preferences scale.

\section{Patient prosthetic valve knowledge}

Information that patients perceived from the treating physician with regard to prosthetic valve selection was assessed with MC questions and a 1-5 Likert scale.

For a detailed description of the postoperative survey, see online supplementary appendix 2 .

\section{Statistical methods}

Continuous variables were displayed by the mean, SD and range. Discrete variables were displayed as counts or proportions. Multiple imputations (5 iterations) were used to impute missing DCS values. To compare DCS group responses, the Mann-Whitney $\mathrm{U}$ test or Kruskal-Wallis test was used. To compare group responses between patients with a mechanical and bioprosthetic valve, the Mann-Whitney $U$ test or Fisher exact test was used. Patients were allocated to the mechanical or bioprosthetic subgroup according to their survey answer. To compare group responses presurgery and postsurgery, the Wilcoxon signed-rank test was used. All tests were two-sided, and a p value of 0.05 or less was considered statistically significant. All statistical analyses were performed using IBM-SPSS V.20 (IBM Corp., Armonk, New York, USA). 


\section{RESULTS}

\section{Preoperative survey}

One hundred and thirty-two elective adult patients scheduled for AVR in three academic Dutch hospitals participated. Twenty-nine patients reported that they were to receive a mechanical valve, 74 a bioprosthetic valve, 2 a valve repair, and 29 did not know which valve they were going to receive. Table 1 displays patient characteristics. Patients with a bioprosthetic valve were significantly older than patients with a mechanical valve $(p=0.000)$.

\section{Patient experience with prosthetic valve selection}

The preoperative consultation with regard to prosthetic valve choice was performed by the cardiologist (48\%), the surgeon (18\%), the surgeon and cardiologist together $(16 \%)$ or other, for example a resident or physician assistant $(19 \%)$. More than half of the patients $(57 \%)$ involved a friend or family member in prosthetic valve choice. Sixty-four per cent of patients felt they had sufficient time to make a deliberate prosthetic valve choice and $64 \%$ felt they had a prosthetic valve choice.

Table 2 displays the results of the DCS.

There were no significant differences in the total DCS score between patients from the three different hospitals, and between patients with a mechanical versus bioprosthetic valve. The type of medical professional who performed the preoperative consultation did not influence the patient total DCS score. Patients who involved a friend or family member in prosthetic valve choice experienced significantly less decisional conflict than patients who made the decision alone $(\mathrm{p}=0.001)$.

Table 3 displays the patient's valuation of the importance of the different risks and benefits associated with mechanical and bioprosthetic valves.

\section{Patient preferences for SDM and risk presentation}

Patient preference for the final decision in prosthetic valve choice is displayed in figure 1 . Sixty-eight per cent

\begin{tabular}{ll} 
Table 1 Patient characteristics & \\
\hline & $\mathbf{n = 1 3 2}$ \\
\hline Age, mean (SD), years & $66.7(12.8)$ \\
Age, range, years & $23-86$ \\
Male sex, $\mathrm{n}(\%)$ & $89(67)$ \\
$\begin{array}{l}\text { Educational level, } \mathrm{n}(\%)(\mathrm{n}=130) \\
\quad \text { High school }\end{array}$ & $45(35)$ \\
High school graduate & $55(42)$ \\
College graduate & $27(21)$ \\
$\quad$ Other & $3(2)$ \\
Hospital, $\mathrm{n}(\%)$ & \\
1 & $57(43)$ \\
2 & $55(42)$ \\
3 & $20(15)$ \\
Referral to academic hospital, $\mathrm{n}(\%)(\mathrm{n}=129)$ & \\
$\quad$ Other hospital & $114(88)$ \\
General practitioner & $15(12)$ \\
\hline
\end{tabular}

\begin{tabular}{ll}
$\begin{array}{l}\text { Table } 2 \text { Preoperative score on Decisional Conflict Scale } \\
\text { (DCS) }\end{array}$ \\
\hline $\mathrm{N}(\%)$ with total score on DCS \\
$\quad<25$ & $58(44)$ \\
$25-37.5$ & $41(31)$ \\
$>37.5$ & $33(25)$ \\
Mean (SD) score on DCS subscales: & \\
$\quad$ Uncertainty & $33.6(24.9)$ \\
$\quad$ Informed & $22.3(25.3)$ \\
Values clarity & $29.3(23.5)$ \\
Support & $24.0(23.5)$ \\
Effective decision & $13.0(18.4)$ \\
\hline
\end{tabular}

Total score <25: no decisional conflict and implementation of decision.

Total score $\geq 25$ : decisional conflict.

Total score $\geq 37.5$ : decision delay or feeling unsure about implementation.

of patients wanted to be involved in decision-making, whereas $53 \%$ agreed that they were actually involved.

The majority of patients $(68 \%)$ preferred scientific evidence presentation in a pie chart, followed by the horizontal bar, and the two pictographs.

\section{Patient prosthetic valve knowledge}

Ninety-nine per cent of patients were aware that there are different types of aortic valve prostheses and $80 \%$ reported knowing which valve they were going to receive. Fifty-nine per cent were of the opinion that they had sufficient knowledge about the different types of aortic valve prostheses.

Table 4 displays patient prosthetic valve knowledge and numeracy.

Ninety-eight per cent of patients $(n=129)$ answered all three questions concerning prosthetic valve knowledge. Of these, $5 \%$ were not able to answer any of the three questions correctly, $9 \%$ were able to answer one question correctly, and $16 \%$ and $69 \%$ were able to answer two and three questions correctly, respectively. There were no significant differences between patients with a mechanical and bioprosthetic valve. Sixty-four per cent of patients $(n=84)$ answered all three numeracy questions. Four per cent were not able to answer any of the three questions correctly, $12 \%$ were able to answer one question correctly, $29 \%$ were able to answer two questions correctly and $56 \%$ were able to answer three questions correctly. There were no significant differences between patients with a mechanical and bioprosthetic valve.

\section{Postoperative survey}

One hundred and ten patients responded to the postoperative survey. Reasons for loss to follow-up included death $(n=4)$, inability to complete the survey due to morbidity $(n=5)$, cancelled operation due to comorbidity $(n=2)$ or non-response $(n=11)$. At the time of the postoperative survey, $86 \%$ of patients $(n=95)$ were in NYHA class I or II, and $14 \%$ of patients $(n=15)$ were in NYHA class III or IV. Twenty-eight patients reported that 
Table 3 Patient valuation of the importance of the different risks and benefits associated with a mechanical (MP) and bioprosthetic (BP) valve

\begin{tabular}{|c|c|c|c|}
\hline & Total (\%) & MP (\%) & BP $(\%$ \\
\hline \multicolumn{4}{|c|}{ I am concerned about a possible bleeding } \\
\hline (Totally) agree & 23 & 24 & 21 \\
\hline Not agree/disagree & 18 & 28 & 16 \\
\hline (Totally) disagree & 27 & 31 & 24 \\
\hline Do not know* & 31 & 17 & 39 \\
\hline \multicolumn{4}{|c|}{ I am afraid of blood clots } \\
\hline (Totally) agree & 24 & 21 & 23 \\
\hline Not agree/disagree & 20 & 24 & 23 \\
\hline (Totally) disagree & 32 & 45 & 26 \\
\hline Do not know & 24 & 10 & 29 \\
\hline \multicolumn{4}{|c|}{ I have problems with taking medication } \\
\hline (Totally) agree & 9 & 7 & 7 \\
\hline Not agree/disagree & 6 & 7 & 4 \\
\hline (Totally) disagree & 75 & 82 & 72 \\
\hline Do not know & 11 & 4 & 17 \\
\hline \multicolumn{4}{|c|}{ I am afraid that I may need another valve operation } \\
\hline (Totally) agree & 23 & 45 & 20 \\
\hline Not agree/disagree & 13 & 21 & 9 \\
\hline (Totally) disagree & 41 & 31 & 44 \\
\hline Do not know* & 23 & 3 & 28 \\
\hline \multicolumn{4}{|c|}{ I am afraid that my valve may fail } \\
\hline (Totally) agree & 13 & 28 & 11 \\
\hline Not agree/disagree & 11 & 21 & 8 \\
\hline (Totally) disagree & 55 & 45 & 54 \\
\hline Do not know* & 22 & 7 & 26 \\
\hline
\end{tabular}

I am afraid that I will be limited by my new heart valve in my daily activities

$\begin{array}{lllr}\text { (Totally) agree } & 12 & 24 & 6 \\ \text { Not agree/disagree } & 10 & 14 & 6 \\ \text { (Totally) disagree } & 58 & 52 & 64 \\ \text { Do not know } & 20 & 10 & 25\end{array}$

I am afraid that my new heart valve will negatively influence my social life

$\begin{array}{lrrr}\text { (Totally) agree } & 5 & 3 & 7 \\ \text { Not agree/disagree } & 12 & 24 & 4 \\ \text { (Totally) disagree } & 65 & 62 & 67 \\ \text { Do not know } & 18 & 10 & 22\end{array}$

It bothers me that I have to use oral anticoagulation lifelong

$\begin{array}{lrrr}\text { (Totally) agree } & 53 & 45 & 57 \\ \text { Not agree/disagree } & 9 & 7 & 6 \\ \text { (Totally) disagree } & 27 & 38 & 23 \\ \text { Do not know } & 12 & 10 & 14 \\ \text { am afraid that the valve sound will bother me } & \\ \text { (Totally) agree } & 34 & 38 & 34 \\ \text { Not agree/disagree } & 14 & 21 & 10 \\ \text { (Totally) disagree } & 28 & 34 & 24 \\ \text { Do not know } & 24 & 7 & 31\end{array}$

* $p<0.05$ proportion of patients answering 'do not know' in mechanical versus bioprosthetic valve groups.

they received a mechanical valve, 81 a bioprosthetic valve and 1 a valve repair.

Patient experience with prosthetic valve selection

Seventy-seven per cent of patients felt they had sufficient time to make a deliberate prosthetic valve choice, which

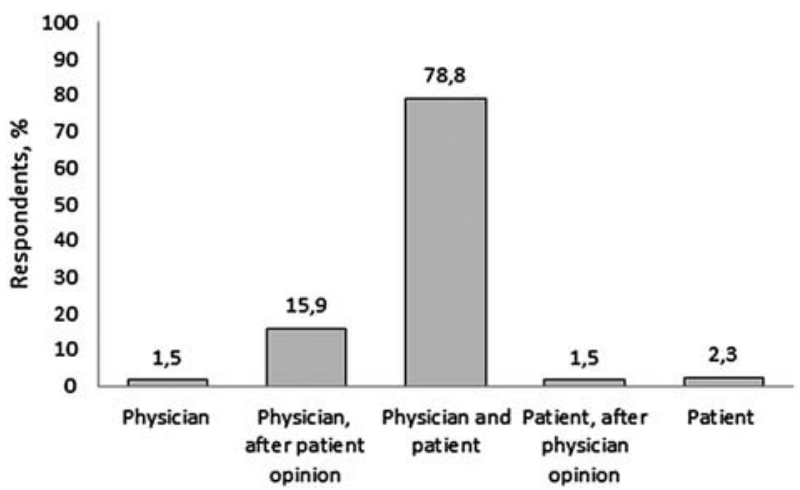

Figure 1 Preoperative patient preference for final decision in prosthetic aortic valve choice $(n=132)$.

was significantly higher than preoperatively $(p=0.001)$. Seventy-four per cent of patients felt they had a prosthetic valve choice ( $p=\mathrm{NS}$ compared with preoperative).

Ninety per cent were satisfied with their valve prosthesis, $7 \%$ did not have an opinion and $4 \%$ were unsatisfied. There was no difference between patients with a mechanical and bioprosthetic valve.

The results of the valve-specific questionnaire are displayed in table 5 .

\section{Patient preferences for SDM}

Eighty-seven per cent of patients wanted to be involved in decision-making, whereas $74 \%$ agreed that they were actually involved. This was significantly higher than preoperatively (68\% vs $87 \%$; $\mathrm{p}=0.000$, and $53 \%$ vs $74 \%$; $\mathrm{p}=0.000$, respectively). Seventy-nine per cent preferred the final prosthetic valve choice to be a shared decision process ( $\mathrm{p}=\mathrm{NS}$ compared with preoperative).

\section{Patient prosthetic valve knowledge}

Ninety-nine per cent of patients were aware that there are different types of aortic valve prostheses and $100 \%$ reported knowing which valve they received. Seventy-four per cent were of the opinion that they had sufficient knowledge about the different types of aortic valve prostheses ( $\mathrm{p}=\mathrm{NS}$ compared with preoperative).

\section{DISCUSSION}

In current Dutch cardiovascular clinical practice, patients who require AVR often experience decisional conflict and suboptimal involvement in prosthetic valve selection, and exhibit impaired numeracy. The majority of patients want to be involved in prosthetic valve selection, while only half of the patients actually feel involved. Given the limited patient knowledge of prosthetic valves and numeracy, there is an obvious need for improved information conveyance on prosthetic valve options and their associated risks and benefits.

\section{Patient experience with prosthetic valve selection}

The quality of decision-making does not appear to be influenced by the physician who discusses prosthetic 
Table 4 Preoperative prosthetic valve knowledge and basic numeracy

Correct

(\%)

Prosthetic valve knowledge $(n=129)$

1. Which valve type is most durable?

84

2. Which valve type is associated with

72 increased risk of blood clots?

3. Which valve type requires lifelong anticoagulation?

Basic numeracy questions $(n=84)$

1. Convert $1 \%$ to 10 in 1000

87

2. Convert 1 in 1000 to $0.1 \%$

61

3. How many heads in 1000 coin flips?

89

valve selection, but our study results suggest that it is important for patients to involve a friend or relative, as this will reduce decisional conflict. This is in alignment with the 2014 ACC/AHA Valvular Heart Disease

\section{Table 5 Postoperative answers to a valve-specific} questionnaire

Total (\%) MP (\%) BP (\%)

If I had to do it over again, would I make the same

decision to have surgery?

$\begin{array}{llrl}\text { Yes/probably } & 85 & 85 & 85\end{array}$

$\begin{array}{llll}\text { I do not know } & 11 & 7 & 13\end{array}$

$\begin{array}{llll}\text { Probably not/absolutely not } & 4 & 7 & 3\end{array}$

Is there a valve sound that bothers me?*

$\begin{array}{llll}\text { Frequently/always } & 6 & 22 & 0\end{array}$

Occasionally $\quad 11 \quad 32 \quad 4$

$\begin{array}{llll}\text { Never/rarely } & 83 & 47 & 96\end{array}$

Following my valve surgery, the frequency of doctor visits and blood tests bothers me

$\begin{array}{llll}\text { Frequently/always } & 8 & 14 & 6\end{array}$

$\begin{array}{llll}\text { Occasionally } & 25 & 29 & 24\end{array}$

$\begin{array}{llll}\text { Never/rarely } & 67 & 57 & 70\end{array}$

The possibility of complications due to my implanted valve concerns me

Frequently/always $\quad 4 \quad 4 \quad 4 \quad 4$

$\begin{array}{llll}\text { Occasionally } & 26 & 29 & 25\end{array}$

Never/rarely $\quad 70 \quad 68 \quad 71$

I am concerned about possible bleeding caused by my anticoagulant medication

$\begin{array}{lrrr}\text { Frequently/always } & 7 & 11 & 5 \\ \text { Occasionally } & 25 & 32 & 23 \\ \text { Never/rarely } & 69 & 57 & 73\end{array}$

I am afraid that my valve may fail

Frequently/always $\quad 3 \quad 4 \quad 4$

$\begin{array}{llll}\text { Occasionally } & 16 & 18 & 15\end{array}$

Never/rarely $\quad 82 \quad 79 \quad 83$

I am afraid that I may need another valve operation

$\begin{array}{lrrr}\text { Frequently/always } & 5 & 4 & 5 \\ \text { Occasionally } & 22 & 7 & 27 \\ \text { Never/rarely } & 74 & 89 & 68\end{array}$

${ }^{*} \mathrm{p}<0.05 \mathrm{MP}$ versus $\mathrm{BP}$ groups.

$\mathrm{BP}$, bioprosthetic valve; MP, mechanical valve.
Guidelines that highlight the importance of involving family members in decision-making. ${ }^{2}$

Preoperatively, one-third of patients in this study felt they did not have sufficient time to make a deliberate prosthetic valve choice, and/or felt like they did not have a choice at all. This observation indicates room for improvement in decision-making, allowing for sufficient time and adequate information conveyance. Postoperatively, significantly more patients felt they had sufficient time than preoperatively. It is possible that preoperative stress may have influenced patient perception regarding the amount of time needed for prosthetic valve choice.

More than half of the patients experienced decisional conflict, and one in four patients to such an extent that it made them feel unsure about the decision. Decisional conflict was most evident in the uncertainty and values clarity subscales, suggesting that particular measures aimed at reducing patient uncertainty and improving value clarification will be effective in improving decisionmaking quality. ${ }^{6}$ Patient satisfaction with the selected prosthetic valve did not appear to be affected by the suboptimal decision-making. This may be caused by the phenomenon of choice closure: the process by which people come to perceive a decision to be resolved and complete. As choice closure results in greater satisfaction, it can explain at least in part why most patients were satisfied with their prosthetic valve. ${ }^{11}$

Preoperatively, the most common patient concerns about complications were related to the use of lifelong oral anticoagulation, the risk of bleeding or blood clot, valve sound and the need for a reoperation. Therefore, these topics require particular attention in the preoperative consultation. Interestingly, patients with a bioprosthetic valve more often answered 'do not know' when they were asked about complications. This may be due to their older age as it is known that older patients usually have a more passive role in decision-making and more difficulties understanding medical information. ${ }^{12} 13$

\section{Patient preferences for SDM and risk presentation}

A common misperception among clinicians is that many patients do not want to be involved in decisionmaking. ${ }^{14}$ The current study shows the contrary: most of the patients who require AVR do want to be involved. Previous studies in different medical fields also show that patients prefer to be involved in decisionmaking. ${ }^{15}{ }^{16}$ In our study, more patients felt involved in decision-making postoperatively than preoperatively. The preoperative survey was conducted after preoperative outpatient counselling, on average 2 weeks before the operation. It is possible that patients received more information about prosthetic valve selection in the remaining time prior to and following the operation.

SDM receives more and more attention in healthcare. It can be described as a meeting of experts, the clinician as an expert on the medical issues and the patient as an expert on their values and preferences. ${ }^{4}$ SDM has several advantages, like increased patient knowledge, less 
patient anxiety, improved health outcomes, reductions in care and cost variation and more alignment of care with patient values. ${ }^{17}$ Therefore, it is not surprising that the 2014 ACC/AHA Valvular Heart Disease Guidelines and the $2012 \mathrm{ESC} / \mathrm{EACTS}$ guidelines state that SDM is a Class I recommendation for prosthetic valve selection. ${ }^{1}{ }^{2}$ Nevertheless, despite the advantages of SDM and the fact that the guidelines advocate SDM, informed SDM is not often applied in daily clinical practice. ${ }^{18}{ }^{19}$ SDM can be time-consuming and requires extra effort, which can be a barrier for cardiovascular professionals. In this respect, the use of a decision aid (DA) may be useful to support SDM. It has been shown that patients who use a DA have improved knowledge, more accurate risk perception, reduced decisional conflict and are more likely to receive care that is in line with their personal values. ${ }^{17}$ In the setting of prosthetic valve selection, a DA can inform patients about the different prosthetic valves and associated risks and benefits, help them clarify their preferences and guide them through the decision-making.

In order to participate in decision-making, patients should be able to understand what the available prosthetic valve options and their associated risks and benefits are. The way risks and benefits are presented influences the ability of the patient to understand the given information. Presenting statistical information in a graphical instead of numerical format increases people's understanding and may affect their decision-making. ${ }^{20}$ Previous studies show that a pictograph is the preferred option to present probabilistic information to patients. ${ }^{8}$ In this study, however, most patients preferred a pie chart. Of note, this study only investigated patient preference for the presentation of scientific evidence, while previous studies investigated which graph format achieved the best accuracy of risk perception. Therefore, although most patients in our study preferred a pie chart, this does not necessarily imply that it is the most effective way to communicate risks.

\section{Patient prosthetic valve knowledge and numeracy}

Almost half of the patients in our study felt that they had insufficient knowledge of prosthetic valves and almost one-third were unable to answer three basic knowledge questions about prosthetic valves correctly. We can only hypothesise that they either were not informed about the different prosthetic valves or received information that they were unable to comprehend. This observation nevertheless calls for the development of information provision on prosthetic valves that is tailored to the needs of patients.

Besides testing patient knowledge, we also deliberately tested numeracy. Since numbers are an inherent part of weighing risks and benefits, ${ }^{9}$ numeracy is of great influence on the capacity of patients to engage in SDM. One-third of the study patients did not answer any basic numeracy question. It could be that the questions were perceived too difficult and patients were afraid to answer them. Additionally, nearly half of the patients who did answer all numeracy questions exhibited impaired numeracy. These observations underline the importance of recognition among physicians that many patients have difficulties understanding numbers and need help in understanding the risks and benefits of treatment options. ${ }^{21}$

Given their limited basic knowledge regarding prosthetic valves and limited numeracy, many patients will experience difficulties in weighing the risks and benefits associated with mechanical and bioprosthetic valves. A DA with plain language, absolute risks presented as frequencies, and pictographs used to communicate risks and benefits ${ }^{20}$ may therefore be helpful in the setting of prosthetic valve selection. Building on this study and a previous survey concerning SDM in prosthetic valve selection among Dutch cardiovascular professionals, ${ }^{5}$ an information portal and DA for prosthetic valve selection has been developed and is currently being tested in a multicentre randomised controlled trial (RCT) to assess whether the use of the DA indeed improves the quality of decision-making and patient outcome in the setting of prosthetic valve selection.

\section{Study limitations}

This study population represents Dutch academic cardiovascular clinical practice. A limitation of the study was the relatively small sample size. Furthermore, surveys were completed at home and patients may have been influenced by family members or friends. Finally, it is possible that only the more motivated patients may have completed the questionnaire, which could introduce selection bias.

In conclusion, this study illustrates that in current Dutch cardiovascular practice, patients who require AVR experience suboptimal involvement in prosthetic valve selection, and exhibit impaired knowledge concerning prosthetic valves and numeracy. Given the broad support for SDM among patients and the cardiovascular community, and the obvious need for understandable information, implementation in clinical practice of the concept of SDM would be a major step forward in improving clinical decision-making in prosthetic valve selection. This will result in better patient involvement in decisions, increased patient knowledge, involvement and satisfaction and perhaps even a better QoL.

Acknowledgements The authors would like to thank all the patients who participated in this study.

Competing interests None.

Ethics approval Erasmus MC.

Provenance and peer review Not commissioned; externally peer reviewed.

Data sharing statement No additional data are available.

Open Access This is an Open Access article distributed in accordance with the Creative Commons Attribution Non Commercial (CC BY-NC 4.0) license, which permits others to distribute, remix, adapt, build upon this work noncommercially, and license their derivative works on different terms, provided the original work is properly cited and the use is non-commercial. See: http:// creativecommons.org/licenses/by-nc/4.0/ 


\section{REFERENCES}

1. Vahanian A, Alfieri O, Andreotti F, et al, Joint Task Force on the Management of Valvular Heart Disease of the European Society of Cardiology (ESC); European Association for Cardio-Thoracic Surgery (EACTS). Guidelines on the management of valvular heart disease (version 2012). Eur Heart J 2012;33:2451-96.

2. Nishimura RA, Otto CM, Bonow RO, et al. 2014 AHA/ACC guideline for the management of patients with valvular heart disease: a report of the American College of Cardiology/American Heart Association Task Force on Practice Guidelines. Circulation 2014;129:e521-643.

3. Brennan JM, Edwards FH, Zhao Y, et al. Long-term safety and effectiveness of mechanical versus biologic aortic valve prostheses in older patients: results from the Society of Thoracic Surgeons Adult Cardiac Surgery National Database. Circulation 2013;127:1647-55.

4. Ruel M, Chan V, Bedard P, et al. Very long-term survival implications of heart valve replacement with tissue versus mechanical prostheses in adults \&lt;60 years of age. Circulation 2007;116:I294-300.

5. Korteland NM, Kluin J, Klautz RJ, et al. Cardiologist and cardiac surgeon view on decision-making in prosthetic aortic valve selection: does profession matter? Neth Heart J 2014;22:336-43.

6. O'Connor AM. Validation of a decisional conflict scale. Med Decis Making 1995;15:25-30.

7. Degner LF, Sloan JA, Venkatesh P. The control preferences scale. Can J Nurs Res 1997;29:21-43.

8. Hawley ST, Zikmund-Fisher B, Ubel P, et al. The impact of the format of graphical presentation on health-related knowledge and treatment choices. Patient Educ Couns 2008;73:448-55.

9. Lipkus IM, Samsa G, Rimer BK. General performance on a numeracy scale among highly educated samples. Med Decis Making $2001 ; 21: 37-44$
10. Aicher D, Holz A, Feldner S, et al. Quality of life after aortic valve surgery: replacement versus reconstruction. J Thorac Cardiovasc Surg 2011;142:e19-24.

11. Gu YJ, Botti S, Faro D. Turning the page: the impact of choice closure on satisfaction. J Consum Res 2013;40:268-83.

12. Arora NK, McHorney CA. Patient preferences for medical decision-making: who really wants to participate? Med Care 2000;38:335-41.

13. DeVoe JE, Wallace LS, Fryer GE Jr. Patient age influences perceptions about health care communication. Fam Med 2009;41:126-33.

14. Ting $\mathrm{HH}$, Brito JP, Montori VM. Shared decision-making: science and action. Circ Cardiovasc Qual Outcomes 2014;7:323-7.

15. Albrecht KJ, Nashan D, Meiss F, et al. Shared decision-making in dermato-oncology: preference for involvement of melanoma patients Melanoma Res 2014;24:68-74.

16. Uldry E, Schafer M, Saadi A, et al. Patients' preferences on information and involvement in decision-making for gastrointestinal surgery. World J Surg 2013;37:2162-71.

17. Lee EO, Emanuel EJ. Shared decision-making to improve care and reduce costs. New Engl J Med 2013;368:6-8.

18. Hauptman PJ, Chibnall JT, Guild C, et al. Patient perceptions, physician communication, and the implantable cardioverter-defibrillator. JAMA Intern Med 2013;173:571-7.

19. Zikmund-Fisher BJ, Couper MP, Singer E, et al. Deficits and variations in patients' experience with making 9 common medical decisions: the DECISIONS survey. Med Decis Making 2010;30:85S-95S.

20. Fagerlin A, Zikmund-Fisher BJ, Ubel PA. Helping patients decide: ten steps to better risk communication. J Natl Cancer Inst 2011;103:1436-43.

21. Gigerenzer G. Making sense of health statistics. Bull World Health Organ 2009;87:567. 